\title{
Measuring eco cities, comparing European and Asian experiences: Rotterdam versus Beijing
}

\author{
Meine Pieter van Dijk
}

Received: 3 November 2011 /Revised: 14 November 2014 / Accepted: 24 November 2014 / Published online: 4 January 2015

C) The Author(s) 2015. This article is published with open access at Springerlink.com

\begin{abstract}
Many cities have taken initiatives to achieve more sustainable development or to become ecological cities. In this paper, ten dimensions are suggested for defining ecological cities and an effort has been made to provide indicators to measure them. Many cities claim to be ecological cities, but there are no non-ambiguous definitions of ecological cities and few efforts have been made to measure to what extent the cities have achieved their goal. This paper considers the efforts of Beijing and Rotterdam to become more eco cities, using these dimensions. What can we learn from these experiences for developing the city of the future? In an illustrative effort to apply the suggested criteria, Rotterdam scored slightly better than Beijing. The latter city is facing more serious environmental problems and is willing to try more innovative solutions, while Rotterdam spends more money on prevention and $\mathrm{CO}_{2}$ reduction.
\end{abstract}

\section{Introduction}

Different climate change scenarios combined with increased pollution reveal the threat of temperature increases, more rain or bigger droughts for cities. Climate change forces cities to go for mitigation activities or for climate adaptation. Cities aware of their environmental challenges have introduced policies and programs to deal with these issues. They want to become more ecological or eco cities. Earlier efforts to come up with a definition of an eco city have been undertaken. ${ }^{1}$ We will suggest using ten dimensions to define ecological cities and operationalize them to allow measurement of the ecological character of an Asian city and a European city. The dimensions range from the use of energy to how to deal with

${ }^{1}$ For example, by Kenworthy (2006) and Bhatnagar (ed., 2010).

M. P. van Dijk (ه)

UNESCO-IHE Institute for Water Education, Delft, Netherlands

e-mail: mpvandijk@iss.nl

M. P. Dijk

e-mail: m.vandijk@unesco-ihe.org

M. P. van Dijk

ISS, Erasmus University, Rotterdam, Netherlands 
climate change issues in an integrated way. The criteria chosen will then be used to determine to what extent a European city and an Asian city can be called an ecological city. This is an effort to study the metabolism of a city by finding the right indicators.

\section{Issues faced: why more ecological cities}

Bhatnagar (ed., 2010) gives an overview of visions of an eco city, emphasizing criteria like a city accessible for everyone; in balance with nature; reducing, reusing and recycling waste; contributing to a closed water cycle; and integrated into the surrounding region. More visions are possible, but it seems that an effort should be made to list the most important criteria and then to classify which cities would score high on these criteria. We will now introduce the main issues which have led to the choice of ten dimensions as shown in Table 1. The literature concerning each issue will be used to suggest criteria for the operationalization of the dimensions.

\section{Energy issues}

Carbon emissions have drawn a lot of attention because they contribute to climate change. It draws the attention to the importance of the source of energy used. Energy management would also be part of a more ecological city. It usually means reducing greenhouse gas emissions. Indeed, the increased energy use and the resulting $\mathrm{CO}_{2}$ emissions are an important reason for climate change, which has an indirect negative effect on cities. Very often urban policies focus on $\mathrm{CO}_{2}$ reduction. Kennedy and Sgourdis (2011) rightly emphasize the need to come up with a rigorous classification of different emissions and an agreement on carbon accounting principles (which sectors produce how much emission of what in a direct or indirect way) to achieve the ideal of a low or zero-carbon city. SmithMorris (2011) shows how in the 'new urbanism' in England $\mathrm{CO}_{2}$ reduction played an important role. Different projects wanted zero-carbon buildings, and the eco-town concept only later broadened its meaning by including other dimensions. There is an extensive use of environmental technologies for energy management to see to it that cities become closed loop systems, requiring as little outside energy as possible.

How do we measure how the city deals with energy issues? Different indicators will be suggested. Glaeser and Kahn (2010) focus on the actual $\mathrm{CO}_{2}$ emissions in urban areas and the possibility to reduce them, but we should also look at energy saving at the

Table 1 Ten dimensions of an eco city based on urban environmental issues mentioned in the literature

\footnotetext{
1. How does the city deal with energy issues?

2. How does the city deal with solid waste issues?

3. How does the city deal with transport issues?

4. How does the city deal with pollution issues?

5. How does the city deal with water-related issues?

6. How does the city deal with sanitation issues?

7. How does the city deal with climate change issues?

8. How does the city deal with housing issues?

9. How does the city deal with sustainability issues?

10. Does the city follow an integrated approach?
} 
household level, at efforts to reduce greenhouse gas emissions and to introduce renewable sources of energy. Measurement would also require the use of other indicators, such as the use of solar energy (for example solar panels), the use of wind energy (of which the production should ideally be allowed to be ploughed back in the network) and a registration of the use of heating and cooling systems, using underground or river water. In short, the question is what does a city have to achieve in terms of energy reduction to be called an eco city?

\section{Solid waste issues}

Solid waste is an important issue in cities. Dealing with waste in a different way is required, for example, because waste can also block drains, which can lead to flooding (Schubeler et al. 1996). Solid waste is also an important issue because waste can cause health hazards (Usunju et al. 2011). Solid waste minimization and integrated waste management are important and would contribute to a more eco city. Nine indicators are suggested in Table 2 .

\section{Transport issues}

Goods and people move in and out of cities using infrastructure and different modes of transportation. However, there are many infrastructural options and different modes of transportation and some are more environmentally friendly than others. The choice between these different modes is often conditioned by history, culture and climate. In some countries, bicycles have survived because a proper infrastructure was provided (separate bicycle lanes) or the current regulation protects cyclists (in the Netherlands), while in China, the use of bicycles is declining, given busy roads and long distances.

Most of Kenworthy's (2006, p. 68) list of dimensions for the sustainable development of a city in the Third World deal with infrastructure and transportation. He emphasizes the need to move away from a car-dominated city and to build cities around foot paths, bicycle lanes and public transportation. In an eco city, "a freeway and road infrastructure is deemphasized in favour of transit, walking and cycling infrastructure, with a special emphasis on rail. Car and motorcycle use are minimized. ...The central city and sub-centres within the city are human centres that emphasize access and circulation by modes of transport other than the automobile, and absorb a high proportion of employment and residential growth. ... The city has a high quality public culture, community, equity and good governance. The public realm includes the entire transit system and all the environments associated with it".

Transport is an important issue, since it is crosscutting: it has to do with different means of transportation and their fuel consumption and with the physical planning and design of a city. Transport can be an important source of air pollution and causes a lot of noise. Finally, transportation is an important issue in physical planning, which can also help to deal with the issue. Indicators chosen are the use of bicycles and cars in the city and the efforts made to come to an integrated transport policy. Integrated transport policies are desired, but often specialized departments and different levels of government deal with different modes of transportation and different types of roads. What has been achieved in terms of reducing travel time and congestion? Has a rapid transit 
Table 2 Scores on the criteria for being an eco city, applied for illustrative purposes to Rotterdam and Beijing

Ten dimensions

1. Efforts to limit $\mathrm{CO}_{2}$ emissions

2. Energy management at the household level

3. Less GH gas emissions from transportation

4. Promoting energy saving in industry

5. Public transport on LNG

6. Promoting solar energy (sun boilers)

7. Promoting the use of wind energy

8. Solar and wind energy to be ploughed back into the network

9. Heating and cooling with underground water

Average for nine energy indicators (sub-criteria)

10. Efforts to limit the production of solid waste

11. Integrated waste management

12. Promoting the reuse of waste

13. Promoting the recycling of waste

14. Waste minimization in industrial production

15. Constructing waste collection points

16. Policies on hazardous waste

17. Policies on toxic chemicals

18. Involve private sector in waste collection

Average for solid waste indicators

19. Efforts to limit the use of cars

20. City accessible for everyone

21. Type of road infrastructure

22. Promoting the use of bicycles

23. Promoting modal split (transit)

24. Policies to limit congestion

25. Physical planning includes transport issues

26. Integrated urban design (compact city)

27. Develop integrated transport policies

Average for transport indicators

28. Efforts to limit air pollution from households

29. Efforts to limit water pollution

30. Efforts to limit soil pollution

31. Efforts to limit industrial pollution, smog

32. Efforts to limit noise pollution

33. Efforts to limit other types of pollution

34. Reducing intensive agriculture

35 . Reduce the city's footprint

36. A liveable city: quality of life index

Average for nine pollution indicators

37. Efforts to close the water cycle

38. Measures to deal with flooding
Rotterdam

Beijing

8

8

8

8

8

5

5

5

7

8

6.88

8

8

7

7

8

8

8

8

8

7.77

8

8

7

\section{8}

8

8

7

8

7

7.66

$8 \quad 7$

$8 \quad 7$

8

8

8

8

5

6

8

7.44

5

8

8

6.55

6.88

6.00 8

8

6

5

7

5

5

7

5

7

8

8

8

8

7

7

8

7.33

7

8

5

6

7

8

7

7

7

7

7

5

6

7

5

5

6

6

5

7 
Table 2 (continued)

Ten dimensions

Rotterdam

Beijing

39. Separate drainage and sanitation 8

40. Integrated water resource management 7

41. City promotes water demand management 7

42. Promoting rainwater harvesting

43. Using sustainable urban drains

44. Separate brown and grey water

45. Promoting urban agriculture

Average for nine water-related indicators

8

8

8

5

5

8

46. Efforts to promote eco sanitation

47. Produce energy out of sewer (biogas)

48. Decentralized waste water treatment

49. Use eco-friendly water technologies

50. Appropriate sanitation solutions

51. Developing sanitation value chain

52. Central treatment systems

53. Reuse of grey water on the spot

54. Collective facilities for communities

Average for nine sanitation-related indicators

55. Policy of climate mitigation

56. Policy of climate adaptation

57. Resources available

58. Fair governance structure

59. Available technology

60. Adaptive capacity

61. Leadership

62. Autonomy

63. Acting according to plan

Average for nine climate change indicators

64. Efforts to promote isolation

65. Reduction emissions from home heating

66. City has eco houses and neighbourhoods

67. Separating waste at the household level

68. Reducing GHG from construction industry

69. Using sustainable building materials

70. Natural environment permeates city's spaces

71. Integrated housing systems approach

72. Space for recreational purposes

Average for nine housing-related indicators

73. Promotion sustainable urban development

74. Apply Brundland definition of sustainability

75. Protecting the natural environment

76. Good public culture and sense of community 
Table 2 (continued)

\begin{tabular}{lll}
\hline Ten dimensions & Rotterdam & Beijing \\
\hline 77. Trying to change attitudes of actors & 7 & 7 \\
78. Promote ecological production & 6 & 7 \\
79. Use zoning policies & 7 & 7 \\
80. In balance with nature: green areas & 7 & 6 \\
81. Ecosystem rehabilitation activities & 7 & 7 \\
Average for nine indicators for sustainability & 7.11 & 6.66 \\
82. Document showing an integrated approach & 8 & 7 \\
83. City integrated into the surrounding region & 7 & 7 \\
84. Formulate objectives for justice and equality & 7 & 6 \\
85. Involvement of all stakeholders & 8 & 6 \\
86. Planning for future city is visionary debate & 8 & 7 \\
87. Promoting biodiversity & 6 & 5 \\
88. Promoting wildlife & 6 & 5 \\
89. Accountability towards stakeholders & 8 & 5 \\
90. Urban management philosophy & 8 & 6 \\
Average for nine indicators for integration & 7.33 & 6.00 \\
Average for ten different dimensions & 7.084 & 6.529 \\
\hline
\end{tabular}

system been introduced or an alternative type of transportation been promoted in our eco city?

\section{Pollution issues}

How does the city deal with pollution issues? Eco cities should thrive to have low pollution rates. Policies to deal with air, water and other pollution issues are very important. Indicators can be chosen to measure different types of pollution, or the city's footprint and the resulting score would quantify the quality of urban life and the possibility of reducing the city's footprint (van Dijk and Zhang 2005). Eco cities are often presented as a new green paradise, where it is good to stay and where the negative environmental impact of living and working is reduced. Cities may make an effort to emphasize their ecological nature. Under this dimension, we will consider efforts to create a greener city through conservation and pollution abatement as well as dealing with the consequences of climate change (van Dijk 2011).

\section{Water-related issues}

Due to climate change, cities may face floods or water shortages. Water stress can be noted in many countries (Seckler et al. 1998). A deteriorating environment accelerates the trend towards a gradual shortage of fresh water. While fresh water supplies are clearly limited, for most people, water scarcity is caused by competition between water uses and by political, technological and financial barriers that limit their access to water (Falkenmark and Lundqvist 1998). Cities may have problems with drinking water or 
waste water treatment. Under this dimension, we consider different, more ecological ways of dealing with water and waste.

The approach of Singapore focuses on closing the urban water cycle (Ministry of Information of Singapore 2008), defined as the link between the resource, its use for drinking water and eventual treatment to allow the water to flow back into the resource for reuse. The Millennium Development Goals (MDGs) attempt to address water and waste issues in developing countries by trying to halve the number of people with no access to safe water by 2015 in addition to halving the number of people without access to safe sanitary facilities. The first goal may concern about one billion people, but there are almost two billion people in the world with no access to safe sanitation. Dealing with this issue in a Third World urban context is a real challenge. We want to point to efforts to deal with waste water differently, to promote eco sanitation and the use of collective toilet facilities.

\section{Sanitation issues}

What do changes in available rainwater mean, for example, for drinking water supply and sanitation? Solutions considered for the challenges caused by changes in available rainwater focus on integrated water resource management, which means including waste water in the water cycle (not to lose any water) as argued by the Switch project (Howe et al. 2012). Policies suggested are promoting rainwater harvesting ${ }^{2}$ and different ways of dealing with waste water, for example separating grey and brown water. Criteria to assess the progress on this dimension would be what has been achieved in terms of rainwater harvesting, separating grey and brown water, the introduction of eco toilets, waste water reuse, etc.?

\section{Climate change issues}

How does an eco city deal with climate change issues? Different climate change scenarios combined with increased pollution may lead to temperature increases, more rain or bigger droughts for cities. Climate change forces cities to opt for mitigation activities or for climate adaptation policies. Cities aware of these challenges have introduced policies and programs to deal with climate change. Research points to the importance of policies for climate mitigation and adaptation and of leadership at the local government level to deal with these issues.

\section{Housing-related issues}

Housing policies are not just concerning the numbers of units to be built. It also has to do with the location, the quality and the implications for transport, energy use and pollution abatement. Planners are concerned with the provision of housing, infrastructure and public transport, but financial constraints may prevent them from considering

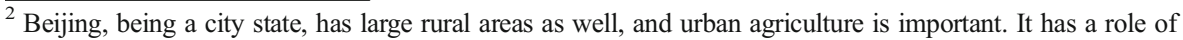
supplying the city with fruits and vegetables, but the question is whether the current way is sustainable. Often groundwater is used, but this is a scarce commodity, its use should be limited, and it could partially be replaced by rainwater.
} 
green options. Eventually, the private investors and project developers have a large say in the implementation stage. Some of them are interested in green features because it may increase the value of their property.

Green cities require sustainable development

Different authors emphasize the importance of a green city or nature conservation (Betancourth 2011). ${ }^{3}$ Brundland (1987) defines sustainable development as the development that meets the needs of the present generation without compromising the needs of the future generations. Achieving the sustainable urban development also includes a different approach to urban infrastructure planning. Trees deserve a place, even if they may hinder the circulation of vehicles. Open and green spaces in an eco city can serve several functions. For that reason, Duc Uy and Nakagoshi (2007) introduce a land suitability analysis to optimize the benefits of urban green spaces. The percentage of green space to total space would give an indication of the success of such policies.

Integration issues

Several chapters in Wong and Yuen (eds., 2011) emphasize the importance of planning of eco cities. Within the urban development, a distinction can be made between the urban planning and the urban management approach. In the first case, the design, the planning process and the resulting urban plan receive most of the attention. The urban management approach emphasizes the importance of putting a plan into practice, with the help of all the relevant stakeholders. The urban manager may take a more activist stand, trying to achieve the necessary investments by promoting participation of all stakeholders (van Dijk 2006, p. 26).

Planning eco cities has its own challenges. How can the eco city be sustainable in the long term, when the issues change and alternative technologies may become available? To manage this process, the involvement of stakeholders in the implementation process is crucial, as argued by urban managers.

For each of these dimensions, a number of sub-indicators will now be suggested based on the literature and the need to find measurable indicators.

The following are the criteria to operationalize the ten dimensions:

1. How does the city deal with energy issues?

The use of energy and the resulting $\mathrm{CO}_{2}$ emissions are an important reason for climate change and the resulting negative effects for cities. We suggest possible indicators to determine how cities deal with energy issues (see Table 2). Glaeser and Kahn (2010) focus on the actual $\mathrm{CO}_{2}$ emissions in urban areas and the possibility to reduce it, but we also look at energy saving at the household level, at efforts to reduce greenhouse gases (GHGs) and to introduce alternative sources of energy.

2. How does the city deal with solid waste issues?

Collecting, transporting, storing and reusing solid waste is an important issue in cities, and dealing with waste in a different way is required. The indicators to

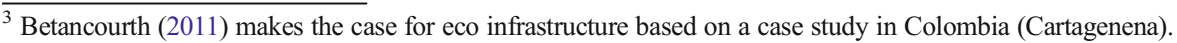


determine how cities deal with solid waste are given in Table 2 and range from promoting the reuse and recycle of waste to integrated waste management policies.

3. How does the city deal with transport issues?

Transport can be an important source of pollution and can cause a lot of noise. Finally, transportation is an important issue in physical planning, which can help to deal with the issue. Indicators chosen are the use of bicycles and cars in the city and the efforts made to come to an integrated transport policy.

4. How does the city deal with pollution issues?

Pollution is the opposite of what you expect in an eco city, and hence, policies to deal with different pollution issues are very important. Indicators chosen in Table 2 are the efforts made to deal with different types of pollution and the resulting score on the quality of urban life and the reduction of the city's environmental footprint.

5. How does the city deal with water-related issues?

We focus on what changes in available water means for drinking water supply and sanitation, but drainage and flooding also need to be considered. Indicators suggested are efforts to close the water cycle and to promote rainwater harvesting. We also look at water resource management and efforts to separate grey and brown water.

6. How does the city deal with sanitation issues?

The MDGs deal with a number of issues. Halving the number of people with no access to save water is one of the goals, just like halving the number of people without access to safe sanitary facilities. The first one may concern about one billion people, but there are almost two billion people in the world with no access to safe sanitation. Dealing with this issue in a Third World urban context is a real challenge. We consider efforts to deal with waste water, to promote eco sanitation and the use of collective toilet facilities.

7. How does the city deal with climate change issues?

Climate change has serious implications for cities and requires climate mitigation and adaptation activities. Relevant questions are how can the projected changes in water supply result in adaptation policies in the concerned cities? Our indicators focus on policies for climate mitigation and adaptation and the leadership of local governments to deal with these issues.

8. How does the city deal with housing issues?

Building, renovating and destructing houses is a huge consequence for the environment. The indicators look at reduction of $\mathrm{CO}_{2}$ emissions and efforts to isolate buildings. However, we also looked whether space is reserved for recreational purposes.

9. How does the city deal with sustainability issues?

There is more emphasis on a more ecological approach to sustainable urbanization. Local governments must think in terms of systems of interrelated components (system engineering). Part of this approach would be developing indicators to monitor constantly the score of the city with respect to the quality of the urban environment and to take corrective actions if certain variables reach threshold levels. 
10. Does the city follow an integrated approach?

Integration could take place in the framework of urban management. Issues discussed are the integration of the different sectoral interests; the role of planning and management; the importance of economic, financial, social and environmental criteria (and how to combine them); who are the decision makers; and how do we deal with the strict and the loose meaning of sustainable urbanization.

\section{Methodology}

Ecological activities in a city can take place at different levels. Four levels will be distinguished: the city, the neighbourhood, the building and the household level. Burnett (2007) remains at the city level when pointing to the possibility of providing eco labels to a city to prove its eco character. The focus could also be on a neighbourhood or a new town. Then we can think of ecological buildings: ecological villas, blocks of houses or apartment buildings with common heating/cooling systems or shared grey water reuse facilities. Finally, individual initiatives can be noted at the household level, installing, for example, sun boilers, spontaneously or triggered by incentives provided by the government.

The reason to pay attention to different sectoral dimensions of eco policies is that often the policy makers and implementing agencies are organized by a sector and integration among the sectors in the implementation stage is a real problem. Energy experts know very little about water, and transport professionals may not think in ecological terms. The focus on the dimensions may mean that we leave out certain aspects of eco city development. Housing policies are, for example, also important because they do not just concern the numbers of units built. These policies also have to do with the choice of a location (what it means for transport), the quality of the house (is it, for example, isolated?) and the implications for $\mathrm{CO}_{2}$ emissions during the construction process.

This paper is based on case studies of Beijing and Rotterdam that were identified using the following criteria:

a. Presented by the authorities or in publications as an example of an eco city

b. The ideas to make it an eco city are actually implemented

c. Possibility of a visit to collect information on the different activities on the ten dimensions and four levels distinguished

d. Possibility to collect data on indicators for the different dimensions of an eco city and the different levels of intervention.

For illustrative purposes, we used the list of indicators to find out if certain initiatives in Asian and European cities qualify for the label ecological city. We have asked 15 elderly inhabitants of Rotterdam to score that city. ${ }^{4}$ In the case of Beijing, two experts from the Switch project were asked to fill in the table. ${ }^{5}$ We suggested a score of 80 or

\footnotetext{
${ }^{4}$ After receiving a 2-h explanation of the criteria used.

5 The average score is calculated by dividing the total score by the number of indicators for which a score has been calculated.
} 
more to qualify for the label eco city. The scores of Beijing and Rotterdam ranged from 1 to 10 and are given in Table $2 .^{6}$

\section{Environmental changes in China and the reaction of Beijing}

Beijing is the capital of China with more than 15 million inhabitants. There are thousands of ecological initiatives to make this city greener. However, there is water scarcity in the north, while water is usually abundantly available in the south of China. Water resources are polluted, drinking water is scarce, and the quality of the water from water treatment plants is not always appropriate for human consumption. Environmental norms have been put at a high level in China but are not always applied seriously.

Policies are developed at the national level in China, and they are implemented in the different provinces, cities and local communities. In the first place, they are made more specific at the level of the city. We like to point to some ecological cities, districts and neighbourhoods which have been built. Secondly, one finds ecological blocks of houses and apartment towers with common heating or cooling systems or a common grey water reuse facility. Finally, individual initiatives should be noted at the household level, spontaneously or triggered by incentives or higher prices of energy or water.

There are risks linked to the current practice of water management for Chinese rivers. CICED (2006) notes that flooding is common just like pollution, while the rivers are also used for irrigation, drinking water, transport and fishing activities. In the northern city of Harbin, an explosion of a petrochemical factory caused an environmental disaster a few years ago. The Songhua River was heavily polluted because benzene ran into the water. Hence, about four million people in Harbin and its neighbouring areas could not use this water any more. The authorities had shut down the drinking water system. The population had to wait until all the polluted water disappeared, and consequently, the population could not drink the water for weeks. This is a big city, and the impact of upstream pollution was enormous. There are water reservoirs to serve the northern cities, but this water was not available at a crucial moment for the inhabitants of Harbin. ${ }^{7}$

In the integrated urban water cycle, managing water resources, drinking water supply and wastewater treatment are three important stages, each with its specific problems in China. The risks in the water cycle are substantial as shown for northern China, where in the big cities, per-capita water consumption is high, probably due to substantial water losses and low tariffs. For that reason, China has embarked on riverlinking projects, which have environmental consequences and may not be economically viable (WWF 2005). The trend in China is to focus on obtaining the most advanced environmental technology to do the job. The emphasis is on the hardware, and not enough attention is paid to managing the existing drinking water supply and waste water treatment systems properly. Hence, many water resources are still polluted, drinking water is scarce, and the quality of the water produced by the water treatment

\footnotetext{
${ }^{6}$ One means no answer, 2 does not know, 3 negative policy, 4 no policy/no awareness of problem, 5 awareness and no policy, 6 some policy, 7 real effort, 8 excellent and 9 perfect policy and impact.

${ }^{7}$ Some northern cities are using desalination plants and also benefit from the south-north river-linking program, which connects the northern Yellow River and the southern Yangtze River.
} 
plants is not always appropriate. To assess the ecological character of Beijing, we use the criteria suggested above.

1. Energy issues in general and $\mathrm{CO}_{2}$ in particular

China did not want to commit itself, during the Copenhagen Climate Conference in 2009, to quantify its reduction of $\mathrm{CO}_{2}$ emissions, but rather, it suggested bringing down the quantity of energy per unit of gross domestic product (GDP). Households in Beijing are asked through TV campaigns to bring back their electricity consumption, and they are encouraged to use sun boilers for heating their water. Isolation of buildings is promoted by subsidies provided from the National Ministry of Construction. In 2009, buying small cars was made more attractive as one way to grow out of the economic recession.

Already before the Olympic Games in 2008, Beijing forced certain polluting and energy (or water)-intensive industries to relocate. This policy contributes to a reduction of energy use and environmental problems in Beijing itself but does not solve the problem at the country level. It is difficult to estimate the effects of these policies. At the national level, it is known that the electricity produced by the Three Gorges Dam was supposed to supply $5 \%$ of the national needs but, currently, only serves half of that, given the rapidly increasing demand for energy.

2. Solid waste issues

Dealing in a proper way with solid waste is important because waste may spread all kinds of diseases. Solid waste is also a source of energy or may be used to recuperate precious raw materials. In Beijing, the government collects waste from collection points, while small private firms and individuals are also collecting and recovering valuable objects. Recycling and reusing is mainly done in the private sector and creates quite a number of jobs. In Beijing, there is a special tax for solid waste, which helps in financing waste collection and processing activities.

3. Transport issues

Transport issues are important to make a big city a good place to live. Beijing has substantially improved its public transportation system for the Olympic Games in 2008 and is trying to reduce the number of new cars by making it more difficult to obtain a license plate for a new car. However, the economic upturn in 2010 has led to a tremendous increase in the number of cars, and China certainly broke a record when it was announced that $100 \mathrm{~km}$ of congested high roads in the direction of Beijing were finally dissolved after 10 days (De Pers, 26 August 2010). Local officials were still cleaning up the debris of lorry drivers who had been camping for days on this high road from Tibet to Beijing.

In Beijing, there are separate bicycle lanes, but cycling is less popular nowadays, because of the risks involved, given the increased number of cars, buses and lorries. Also distances have become bigger because Beijing has extended in all directions and the road infrastructure has been upgraded, in particular, by adding more ring roads around and high roads out of the city. Although the system is well planned and Beijing has invested heavily in infrastructure and transportation, the time spent on congested roads increases all the time. 
4. Pollution issues

The national government has introduced standards for pollution for industries and households, and Chinese provinces have to comply with these standards. Beijing as a city state is at the same administrative level as a Chinese province. The Ministry for the Environment looks after the implementation of environmental policies.

Households have been weaned of using coal for heating purposes, while factories face the applied stricter policies with respect to soil, air and water pollution. Noise pollution is not yet considered as a big issue, but cars are discouraged to use their horns too much. More strict environmental rules have also been applied for housing and the quality of furniture, to avoid that people suffer from the chemicals used. Taken together, Beijing is still considered by many as a relatively dirty city, with dust storms from the northwest and a lot of smog because of all the coals used in electricity generation, automobiles and polluting industries.

5. Water-related issues

A few years ago, Beijing has reorganized its governance structure related to water supply, water management and sanitation. The Beijing Water Authority is the single agency involved, which makes it more efficient than the previous model of various ministries and agencies having the responsibility for waterrelated issues. Beijing is a water scarce area, and as such, it would have interest in closing the water cycle, like what Singapore has done, where, in principle, no water gets lost, but all is reused. ${ }^{8}$ The main reason for not doing this is in China is the lack of confidence of the public in the quality of the water coming from the large-scale centralized waste water treatment plants.

Beijing faces a declining groundwater level, pointing to the overuse of the aquifer below the city. Rainwater harvesting is promoted in the centre of the town and in the rural areas of the city state. It turned out that at the current price of electricity and given that there is no permission necessary and no fee charged for pumping up groundwater, it is cheaper to continue the use of groundwater than to operate rainwater harvesting systems in the rural areas of Beijing (Liang and van Dijk 2011).

Beijing is unique in the world because it has legislation forcing all major new buildings to treat their grey water (from the kitchen and shower) on the spot. The success of this policy is limited, however, since it is cheaper to buy clean municipal water than to make the effort of cleaning grey water and then using it for flushing the toilets and irrigating the garden.

6. Sanitation issues

In Beijing, many public toilets have been built, which are cheap, but usually not free and not always $100 \%$ clean. They also do not always provide the privacy western visitors are used to. No eco sanitation technologies are used, but collective toilets do provide poor people access to safe sanitation. As mentioned, decentralized waste water treatment is encouraged in Beijing for major new buildings, but currently, this is not financially feasible for the investors, although

\footnotetext{
${ }^{8}$ Flooding is not so much the problem, except in the summer of 2012.
} 
it is economically feasible from a society's point of view, if a cost-benefit analysis is carried out (Liang and van Dijk 2010).

7. Climate change issues

China is aware of the dangers of climate change, although climate change is not linked so much to $\mathrm{CO}_{2}$ emissions as well as to water scarcity and the risks of desertification in the north of China. For that reason, Beijing invested in building a green wall to the north of the city, which should stop desertification and diminish the dust storms. The city is also experimenting with aquifer refill and rainwater harvesting projects. Because the use of coal for heating is discouraged, less $\mathrm{CO}_{2}$ is currently coming from that source. Also the relocation of polluting industries should have diminished $\mathrm{CO}_{2}$ emissions in Beijing.

8. Housing issues

Many activities to promote eco cities are at the level of individual households, their house or neighbourhood. China recognizes this by providing, for example, up to $30 \%$ subsidy of the construction cost of ecological housing projects. Such projects would have to save energy (through isolation for example), separate grey and brown water and use temperature exchange equipment, which makes use of the temperature of underground water to heat or cool a building. Often more attention is given to isolating the building than to separating brown and grey water and then treating it on the spot.

9. Green urban development

Sustainability does not seem to be the major principle used for the development of Beijing. For the Olympic Games in 2008, some efforts were made to give a greener impression of the city. On most of the criteria used to measure the sustainable development, Beijing scores low. After cannibalizing the natural resources such as land, water and clean air, Beijing now starts to realize that a greener approach to urban development is necessary. However, just moving polluting industries to other cities is not going to do the job. Even closing 2000 industries (Financial Times, 11 August 2010), showed with the extreme air pollution in 2013, is not to be enough. A number of these industries will open again in the interior of the country, in the underdeveloped western part. Also public campaigns on television are good, but certainly not enough to change the attitudes of households and entrepreneurs, who have been lax as far as sustainable development is concerned.

10. Does Beijing follow an integrated approach?

One notes a large number of disparate initiatives in Beijing to move in the direction of becoming an eco city. However, the city scores low on the indicators for an integrated approach and is hindered by the hierarchical top-down approach of the Chinese administration, which does not stimulate enough initiatives from below.

\section{Rotterdam}

How does Rotterdam in the Netherlands deal with these issues (Rotterdam 2008b)? Rotterdam is the major port of Europe and is connected through the Rhine River and 
the Meuse River with Germany, France and Switzerland. It is also a city threatened by climate change, because of the expected rise of the seawater level or because more water will be coming from the Rhine River and the Meuse River.

Climate change in this case does not only mean dealing with more water but also with more volatility. Rotterdam is trying to become a more ecological city. Rotterdam takes part in the Clinton Climate Initiative and is currently considering storing carbon dioxide in its port area. Rotterdam wants to become a climate-proof city by 2020 (Rotterdam 2008a).

\section{Energy issues}

Rotterdam has different policies to reduce its energy use and to deal with $\mathrm{CO}_{2}$ emissions. The website rotterdamclimateinitiative.nl provides the details. It explains that under the Rotterdam Climate Initiative, the city intends to produce $25 \%$ less $\mathrm{CO}_{2}$ and will try to store $\mathrm{CO}_{2}$ under the ground. By 2025, $50 \%$ less $\mathrm{CO}_{2}$ emissions should be produced. The initiative also wants to promote Rotterdam as a centre of knowledge (on climate), a place to experiment and demonstrate. The website contains also information about the use of cars driven on bioethanol and reports on some experiments with green roofs.

Furthermore, the households are actively advised through municipal staff members how they can reduce their electricity consumption. A speed limit on the ring road does not only limit the fuel consumption of the cars taking this busy road but also brings the noise down to more acceptable levels for the people living next to the high road. The use of alternative sources of energy is still at an infancy stage. In the Netherlands, there is legislation at the national level allowing households and enterprises to feed the electricity they generate back into the national grid. Finally, there are some experiments with using the temperature of the water of the river for heating or cooling purposes, using a heat exchange system.

2. Solid waste issues

Visiting the website Rotterdam.nl (only in Dutch), there are three subjects, under living in Rotterdam, relating to the environment. They are called green, collecting solid waste and water. All the three will be discussed. Under collecting solid waste, all kinds of information are provided concerning this important urban service. In Dutch, the waste from cities is separated at the source. It means that most households do their own composting, and the municipality collects separately the used paper, glass, chemical products, plastic and waste from gardens. Large objects are also collected separately. This has considerably diminished the quantity collected for incineration, while opening the door for more recovery of raw materials.

Rotterdam has an integrated policy of solid waste management. Most of the waste is separated at the source, and a private company is collecting the waste from the households or from common waste collection points. The city also sold its incinerator to a private company, and the electricity they generate is plugged into the national grid.

3. Transport issues

Rotterdam discourages the use of cars in the shopping area in its city centre. It is a compact city and has benefited from integrated urban and transport planning. 
The city has a good ring road and the metro system and tramways imply that it is not necessary to drive to the centre of the city. Parking is possible in big garages or along the major roads but is quite costly. It is hoped that people will use their bike or the excellent public transportation system. In many parts of the city, there are separate bicycle lanes and the central railway station has been rebuilt to allow a larger number of passengers to enter the city. It facilitates 'modal split', the change from one mode of transportation to another. One can change to the metro system, the tramways or buses or park a car or a bicycle at the central station. Even continuing on foot to the cultural and shopping centre is a realistic option, just like renting bikes at the station.

4. Pollution issues

On the website of Rotterdam, one finds under 'green' measures taken to make Rotterdam a green city and, in particular, activities to make the open spaces of schools more green. Rotterdam is quite advanced in its approach to urban pollution. Being a port city, with substantial chemical industries it had already an air quality monitoring system in place for a long time. At several occasions industries had to limit their production during the summer to avoid reaching critical environmental thresholds. Most industries have invested in cleaner technologies since, to avoid these kinds of interruptions.

5. Water-related issues

Rotterdam's problem is, in particular, how to deal with too much water, coming either from the river crossing the city or from the North Sea. The infrastructure for the latter is available in the form of huge sluice doors which can close off the connection with the sea. An automated river water level and pollution monitoring system protects the city from too much and dirty river water. Water storage areas have been designated to serve as areas to be flooded in case the river water would threaten downstream cities, such as Rotterdam.

Every city needs enough drinking water for its population and industries, and hence, it needs water resources. Drinking water consumption is declining in Rotterdam, given meters are now available in every house and water-saving devices are being pushed by the water company and the municipality. However, a city also needs institutions that secure the good use of the water. The current setup in the Netherlands is complicated, and the fragmentation of institutions makes integrated water management at the city level difficult. Given the need for a city like Rotterdam to deal with the risks involved in urban water management, alternative approaches are required like an integrated approach to water management, combining drinking water and surface water management perspectives, which are currently institutionally separated in the Netherlands. Closing the water cycle would mean, in the Dutch context, a closer cooperation between the drinking water utility for the Rotterdam region and the water boards, managing water levels and surface water quality in the Netherlands.

6. Sanitation issues

Rotterdam has a piped sewer system and large-scale waste water treatment plants. The quality of the treated waste water is good enough to use it in a drinking water treatment plant, but this is not yet a common practice in the Netherlands, given that there is no shortage of surface water. 
7. Climate change issues

Rotterdam (2008b) tries to deal with climate issues in its plan 'Rotterdam Climate Proof'. The brochure gives an overview of the main issues for a city wanting to deal with the climate change problem and formulates the challenges for Rotterdam. Then it suggests adaptation for safe Rotterdam and promotes Rotterdam as a centre of knowledge (on climate), a place to experiment and demonstrate.

8. Housing issues

A lot of benefits can be achieved at the level of the house. Isolation is very common in the Netherlands, just like central heating systems for individual houses and apartment buildings. Energy labels for new houses are obligatory. These houses are usually powered by natural gas, which produces very little $\mathrm{CO}_{2}$. Promoting sustainable building materials is now very common, and experiments are carried out with green roofs and providing subsidies for environmentally friendly initiatives, such as the use of LED lights, which is energy saving. Recreational areas are created in the city or close to it, to avoid traffic flows during the weekends and evenings. Within the city, most activities can be reached on foot or by using a bicycle.

9. Green urban development

Rotterdam (2008a, b) describes a number of strategies for sustainable urban development. Sustainability has been a buzz word for the last 20 years, and a number of initiatives can be mentioned. Strict zoning policies help to avoid that living, industrial and commercial areas get mixed up with recreational areas. Parks, dunes and forests are usually open to the public without payment, while primary schools pay a lot of attention to education about nature. The pupils are encouraged to enjoy the parks, dunes and lakes in a responsible way. Degraded ecosystems are usually rehabilitated.

10. Does Rotterdam follow an integrated approach?

It is often claimed that an integrated urban management approach is necessary to deal with issues which are related to each other. This is certainly the case in Rotterdam, where the municipal planning institutions try to involve as many stakeholders as possible. Participatory planning, an emphasis on equal access for everybody and stakeholder involvement are key terms for this approach. Kenworthy (2006) rightly notes that planning for the future of the city should be based on a visionary debate and requires motivated leaders, who are also accountable to their stakeholders.

\section{The comparison between Beijing and Rotterdam}

In our example, Rotterdam scored an average of 7.1 (Table 2) and could still become a more ecological city, where integrated water management would be part of a broader approach to the urban environment. In Rotterdam, a lot is left to the public, to the individual citizens. The term ecological city could be used for an approach to urban management that combines water with environmental management and focuses on long-term urban sustainability. 
Most initiatives in China are taken at the city level, like the promotion of ecological neighbourhoods and innovative housing schemes. Others come from the national level, for example subsidies (30\% of the construction cost in the Chinese case). Finally, initiatives at the household level depend very much on the urgency of the issue and the level of awareness of the people concerned. The initiatives undertaken at different levels show that in China, there is no real integrated approach at the national, provincial, city or neighbourhood level. Provinces are taking the initiative, and provincial capitals are doing some things, while the Ministry of Construction approves the projects in place. People may not always be fully informed about nor involved in these activities. Beijing scored 6.5 but has taken a number of remarkable initiatives (see Table 2).

The people in Beijing and the people in Rotterdam followed a different approach to make their cities more environmentally friendly, but they can learn from each other. Successful experiences can be turned into climate mitigation or adaptation policies to be implemented elsewhere. Urban managers are crucial in tackling these problems and can only do that successfully if local communities are involved. In particular, regulation at the local level reflecting local priorities is important just like taking into account the differences in the stage of economic development as could be seen by comparing the initiatives in Rotterdam to those of Beijing. A lot more is possible within existing urban systems if one is ready to think in terms of creative solutions, using the experiences gained elsewhere. The challenge is to introduce such environmentally and financially sustainable solutions.

The difference in the approaches chosen in Beijing and Rotterdam comes out when comparing the scores. In general, Rotterdam scores slightly better than Beijing, but none of the two cities reaches 80 points. In Beijing, more radical solutions such as separating grey and brown water are tried, while in the Netherlands, a more conservative approach is followed: speed limits, pollution thresholds and energy- and watersaving programs. If China is focusing more on water and promoting rainwater harvesting and the separation of grey and brown water, in Rotterdam, investments are made in energy saving and storing $\mathrm{CO}_{2}$ under the ground. This has to do with the importance of the issues, the level of development and the available money and other resources, but, in particular, with the awareness of these issues among politicians, scientists and common people.

\section{Conclusions}

A more ecological approach to sustainable urbanization implies moving from traditional environmental technologies to more ecosan options in the ecological city of the future. Ecological cities are more than ecologically managed closed urban water systems. Sustainable urban water management is just the beginning. Changes in the behaviour of consumers will be required, just like a combination of better water management, collection and treatment of solid waste and striving towards integration. Water demand management may be a good start at the household level, just like separation at the source, and composting at home is a good start for ecologically friendly solid waste management. Closing the water cycle to deal with water in a more efficient way is an important option. It means not losing any of the scarce resource and 
controlling the quantity and quality constantly. Such an approach would favour integrating the management of the whole water cycle.

What would the ecological city of the future look like? The eco city of the future is not just about dealing with environmental issues. Such a city will also need a sound economic basis, appropriate solutions for its transport systems, its urban services and amenities. There is more and more attention for this dimension of the quality of life in cities, and the presence of sufficient urban services and amenities is an important factor to make a city attractive. In the European Union, this element is emphasized in its program of choosing regularly 'a cultural capital of Europe'. This is usually an opportunity for such a city to show what it has to offer and to make additional investments to increase its attractiveness. All stakeholders need to be involved and motivated. Private developers are looking for new ideas, but mainly interested in saving costs and to make their projects more attractive. The challenge for urban managers is the integration of these different actors and the weighing of the sectoral interests. Ecological cities imply integration of different approaches and sectors in urban planning.

How can eco cities be promoted? Different instruments can be used: incentives, subsidies, demonstration projects and publicity campaigns. Urban development means forging new partnerships between parties that have often not worked together: government officials, non-governmental organizations (NGOs) and private sector businessmen. This requires an ability to develop an integrated approach with all the stakeholders to the key issues facing the city. This is the job of an urban manager. Cities and neighbourhoods differ from one part of the world to another, as anthropologists, nonwestern sociologists and geographers keep telling that economists and, hence, recommendations on how to become a more environmentally friendly city will differ for different cities.

It is important to convince the people that it is essential to do something to improve one's environment. As the Dutch government claimed in a media campaign: The environment starts at home. It will be necessary to focus on more research on the topic of ecological cities as well as finding ways to interest some of the major urban actors in these issues. Good research will show what works and why. It would help to come up with realistic suggestions for ecological cities of the future. However, the coordinating role of local governments and urban managers should not be underestimated. In fact, it is their task to coordinate a multiplicity of actors. That is the essence of urban management: participatory, inclusive and with all actors concerned, taking into consideration equality, the environment and economic development.

Open Access This article is distributed under the terms of the Creative Commons Attribution License which permits any use, distribution, and reproduction in any medium, provided the original author(s) and the source are credited.

\section{References}

Betancourth CH (2011) Eco-infrastructures, feedback loop urbanisms and network of independent zero carbon settlements. In: Wong T-C, Yuen B (eds) Eco-city planning: policies, practice and design. Springer, Berlin, pp 31-51 
Bhatnagar M (ed) (2010) Eco-cities, perspectives and experiences. Icfai University Press, Hyderabad Brundland G (1987) Our common future. United Nations, New York

Burnett J (2007) City building - eco-labels and shades of green. Landsc Urban Plan 83:29-38

CICED (2006) Lessons learned for integrated river basin management. China Environmental Science, Beijing

Duc Uy P, Nakagoshi N (2007) Application of land suitability analysis and landscape ecology to urban green space planning in Hanoi, Vietnam. Urban For Urban Green 7:25-40

Falkenmark M, Lundqvist J (1998) Towards water security: political determination and human adaptation. Crucial Nat Res Forum 21:37-51

Glaeser EL, Kahn ME (2010) The greenness of cities: carbon dioxide emissions and urban development. J Urban Econ 67:404 418

Howe C, Vairavamoorthy K, van der Steen NP (eds) (2012) Sustainable water management in the city of the future. UNESCO-IHE, Delft

Kennedy S, Sgourdis S (2011) Rigorous classification and carbon accounting principles for low and zero carbon cities. Energ Policy 39:5259-5268

Kenworthy JR (2006) 'Dimensions for sustainable city development in the Third World'. Environment Urbanization, pp. 67-86

Liang X, van Dijk MP (2010) Financial and economic feasibility of decentralized waste water reuse systems in Beijing. Water Sci Tech 61:1965-1974

Liang X, van Dijk MP (2011) Economic and financial analysis on rainwater harvesting for agricultural irrigation in the rural areas of Beijing. Resources, Conservation and Recycling 55:1100-1109

Ministry of Information of Singapore (2008), Sustainability. Singapore

Rotterdam (2008) Rotterdam, climate proof. Rotterdam: Municipality

Rotterdam S (2008b) 1600 hectares, creating on the edge, five strategies for sustainable development. Projectbureau Stadshavens Rotterdam, Rotterdam

Schubeler P, Wehrle K, Christen J (1996) Conceptual framework for municipal solid waste management in low-income countries. Swiss Centre for Development Cooperation in Technology and Management, St. Gallen

Seckler D, Amarasinghe U, De Silva R, Barker R (1998) World water demand and supply, 1990-2025: scenarios and issues. IWMI, Colombo

Smith-Morris, E (2011) Down with Eco-towns! Up with eco-communities, or is there a need for model ecotowns? In: Wong, Yuen (eds) A review of the 2009-2010 Eco-town proposals in Britain. pp 113-130

Usunju JB, Schwartz K, Schouten MAC, van Dijk MP, Johnson WP (2011) Slums, socio-economic aspects of improved sanitation in slums. Publ Health 1-9

van Dijk MP (2006) Managing cities in developing countries: the theory and practice of urban management. Edward Elgar, Cheltenham

van Dijk MP (2011) Three ecological cities, examples of different approaches in Asia and Europe. In: Wong TC, Yuen B (eds) Eco-city planning: policies, practice and design. Springer, Berlin, pp 31-51

van Dijk MP, Zhang M (2005) 'Sustainability indices as a tool for urban managers, evidence from four medium-sized Chinese cities'. Environ Impact Assess Rev 25:667-688

Wong T-C, Yuen B (eds) (2011) Eco city planning: policies, practice and design. Springer, Berlin

WWF (2005) Linking rivers. www.riverlinkinsdialogue.org 